\title{
MAKALAH PERMAINAN BOLA VOLI
}

D

I

S

$\mathrm{U}$

S

$\mathrm{U}$

$\mathrm{N}$

\section{OLEH:}

Nama : Daud Hamonangan Tambunan

Kelas : X MIA 3

Mapel : PENJAS

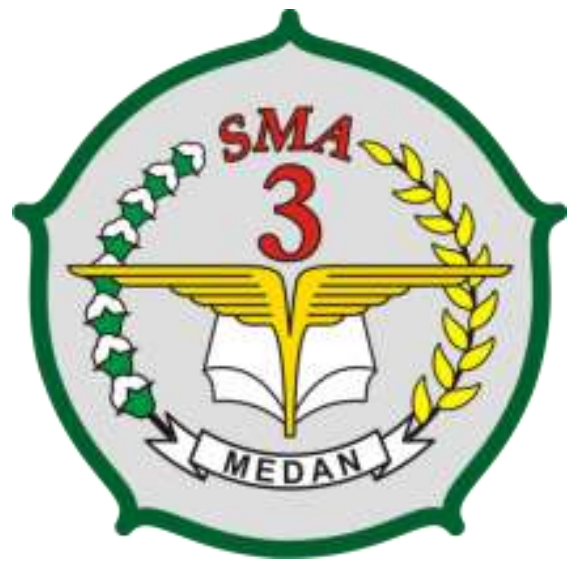

T.A 2018/2019

SMA NEGERI 3 MEDAN

Jln.Budi Kemasyarakatan No.3 Medan 


\section{KATA PENGANTAR}

Puji syukur kehadirat Tuhan Yang Maha Esa atas segala rahmatNYA sehingga makalah ini dapat tersusun hingga selesai . Tidak lupa saya juga mengucapkan banyak terimakasih atas bantuan dari pihak yang telah berkontribusi dengan memberikan sumbangan baik materi maupun pikirannya.

Dan harapan Saya semoga makalah ini dapat menambah pengetahuan dan pengalaman bagi para pembaca, Untuk ke depannya dapat memperbaiki bentuk maupun menambah isi makalah agar menjadi lebih baik lagi.

Karena keterbatasan pengetahuan maupun pengalaman Saya, Saya yakin masih banyak kekurangan dalam makalah ini, Oleh karena itu Saya sangat mengharapkan saran dan kritik yang membangun dari pembaca demi kesempurnaan makalah ini.

Medan, 03 Mei 2020

Daud Hamonangan Tambunan 


\section{DAFTAR ISI}

\section{KATA PENGANTAR}

\section{DAFTAR ISI}

\section{BAB I PENDAHULUAN}
A. Latar Belakang
B. Tujuan
C. Rumusan Masalah

\section{BAB II PEMBAHASAN}
A. Sejarah Bola Voli
B. Pengertian Bola Voli
C. Aturan permainan dari bola voli
D. Teknik Dasar Permainan Bola Voli
E. Posisi Pemain Bola Voli
F. Perasarana Permainan Bola Voli
G. Cara Permainan

\section{BAB III PENUTUP}
A. Kesimpulan
B. Saran

\section{DAFTAR PUSTAKA}




\section{BAB I}

\section{PENDAHULUAN}

\section{A. Latar Belakang}

Pada awal penemuannya, olahraga permainan bola voli ini diberi nama Mintonette. Olahraga Mintonette ini pertama kali ditemukan oleh seorang Instruktur pendidikan jasmani (Director of Phsycal Education) yang bernama William G. Morgan di YMCA pada tanggal 9 Februari 1895, di Holyoke, Massachusetts (Amerika Serikat).

William G. Morgan dilahirkan di Lockport, New York pada tahun 1870, dan meninggal pada tahun 1942. YMCA (Young Men's Christian Association) merupakan sebuah organisasi yang didedikasikan untuk mengajarkan ajaran-ajaran pokok umat Kristen kepada para pemuda, seperti yang telah diajarkan oleh Yesus. Organisasi ini didirikan pada tanggal 6 Juni 1884 di London, Inggris oleh George William.

Setelah bertemu dengan James Naismith (seorang pencipta olahraga bola basket yang lahir pada tanggal 6 November 1861, dan meninggal pada tanggal 28 November 1939), Morgan menciptakan sebuah olahraga baru yang bernama Mintonette. Sama halnya dengan James Naismith, William G. Morgan juga mendedikasikan hidupnya sebagai seorang instruktur pendidikan jasmani. William G. Morgan yang juga merupakan lulusan Springfield College of YMCA, menciptakan permainan Mintonette ini empat tahun setelah diciptakannya olahraga permainan basketball oleh James Naismith. Olahraga permainan Mintonette sebenarnya merupakan sebuah permainan yang diciptakan dengan mengkombinasikan beberapa jenis permainan. Tepatnya, permainan Mintonette diciptakan dengan mengadopsi empat macam karakter olahraga permainan menjadi satu, yaitu bola basket, baseball, tenis, dan yang terakhir adalah bola tangan (handball). Pada awalnya, permainan ini diciptakan khusus bagi anggota YMCA yang sudah tidak berusia muda lagi, sehingga permainan ini-pun dibuat tidak seaktif permainan bola basket. 
Perubahan nama Mintonette menjadi volleyball (bola voli) terjadi pada pada tahun 1896, pada demonstrasi pertandingan pertamanya di International YMCA Training School. Pada awal tahun 1896 tersebut, Dr. Luther Halsey Gulick (Director of the Professional Physical Education Training School sekaligus sebagai Executive Director of Department of Physical Education of the International Committee of YMCA) mengundang dan meminta Morgan untuk mendemonstrasikan permainan baru yang telah ia ciptakan di stadion kampus yang baru. Pada sebuah konferensi yang bertempat di kampus YMCA, Springfield tersebut juga dihadiri oleh seluruh instruktur pendidikan jasmani. Dalam kesempatan tersebut, Morgan membawa dua tim yang pada masing-masing tim beranggotakan lima orang.

Dalam kesempatan itu, Morgan juga menjelaskan bahwa permainan tersebut adalah permainan yang dapat dimainkan di dalam maupun di luar ruangan dengan sangat leluasa. Dan menurut penjelasannya pada saat itu, permainan ini dapat juga dimainkan oleh banyak pemain. Tidak ada batasan jumlah pemain yang menjadi standar dalam permainan tersebut. Sedangkan sasaran dari permainan ini adalah mempertahankan bola agar tetap bergerak melewati net yang tinggi, dari satu wilayah ke wilayah lain (wilayah lawan).

B. Rumusan Masalah

1. Bagaimana sejarah dalam permainan bola voli ?

2. Bagaimana peraturan dalam permainan bola voli ?

3. Berapa ukuran lapangan dalam permainan bola voli ?

C. Tujuan

1. Dapat mengetahui sejarah bola voli

2. Dapat mengetahui peraturan dalam permainan bola voli

3. Dapat mengetahui ukuran lapangan bola voli 


\section{BAB II \\ PEMBAHASAN}

\section{A. Sejarah Bola Voli}

Olahraga bola voli pada saat awal ditemukan dan diberi nama dengan Mintonette. Permaianan bola voli pertama kali ditemukan oleh William G. Morgan yang lahir pada tahun 1870 di Lockport, New York. Disaat itu Morgan bekerja sebagai seorang instruktur pendidikan jasmani (Director of Phsycal Education) tepatnya pada tahun 9 Februari 1895, di Holyoke, Massachusetts Amerika Serikat.

Inspirasi datang ketika Morgan bertemu dengan James Naismith adalah Pencipta olahraga bola basket yang lahir pada tanggal 6 November 1861. Saat itu terciptalah olahraga baru yang bernama Mintonette. Morgan adalah lulusan Springfield College of YMCA dan selama hidupnya Morgan selalu mendedikasikannya sebagai instruktur pendidikan jasmani. Ia menciptakan permainan ini kurang lebih membutuhkan waktu selama empat tahun dengan melakukan kombinasib dari berbagai macam jenis permaianan.

Permaianan Mintonette merupakan gabungan dari empat jenis olahraga yang kemudian dijadikan menjadi satu permaianan. Gabungan empat olahraga tersebut adalah

- Olahraga bola basket

- Olahraga baseball

- Olahraga tenis

- Olahraga bola tangan (handball)

1. Perubahan Nama Mintonette menjadi Volley Ball (Bola voli)

Perubahan nama ini terjadi pada tahun 1896, ketika terjadi demonstrasi pertandingan perdana di International YMCA Training School. Saat itu Director of the Professional Physical Education Training School yang bernama Dr. Luther Halsey Gulick memberikan surat panggilan kepada morgan terkait dengan permaianan yang telah ia ciptakan dan akan dipresentasikan atau didemonstrasikan di stadion kampus yang baru.

Kampus YMCA mejadi tempat dimana diadakanya sebuah konferensi yang di hadiri oleh semua instruktur pendidikan jasmani. Ketika itu Morgan memanfaatkan kesempatan tersebut 
dengan membawa dua tim, dimana setiap tim mempunyai lima orang pemain. kemudian morgan menjelaskan permaianan ini dapat dilakuakan di dalam runagan (indoor) maupun di luar rungan (outdoor) dengan sangat leluasa. Saat itu juga Morgan menjelaskan permainan ini dapat dilakukan oleh banyak pemain tidak memiliki batasan jumlah pemain yang menjadi standar. Permaianan ini dilakukan dengan tujuan mempertahankan bola agar bergerak melewati net yang tinggi dari wilayah ke wilayah lawan.

2. Sejarah permainan Bola Voli di Indonesia

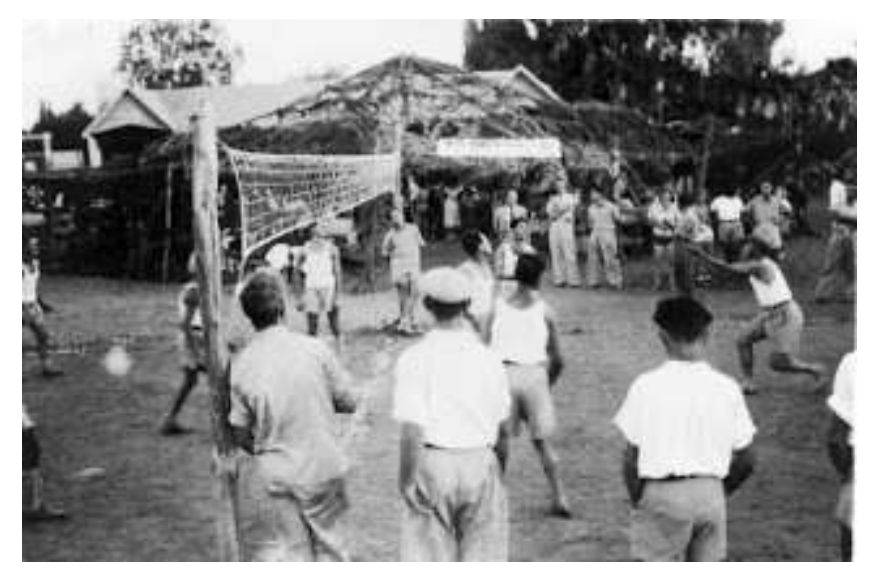

Masuknya permainan bola voli dimulai ketika masuknya masa penjajahan belanda melalui jalur perdagangan pada tahun 1928. Perkembangan permainan bola voli sangatlah begitu cepat di Indonesia, hal ini desebabkan karena kebutuhan olahraga rakyat indonesia yang begitu besar. Maka dari itu permainan bola voli masuk dalam pertandingan pekan olahraga nasional (PON) ke 2 pada tahun 1952 yang diadakan di kota Jakarta. Sampai saat ini bola voli termasuk cabang olahraga resmi yang selalu ada disetiap kejuaraan di Indonesia.

Induk organisasi yang ada di Indonesia yaitu persatuan bola voli seluruh indonesia (PBVSI) berdiri pada tanggal 22 Januari 1955. Dan yang menjabat sebagai ketuanya adalah W. J. Latumenten. Kemudian setelah berdirinya induk organisasi indonesia berdiri, maka pertama kali diadakan sebuah kongres dan kejuaraan nasional yaitu pada tanggal 28 sampai 30 Mei 1955 yang diselenggarakan di Jakarta. 


\section{B. Pengertian Bola Voli}

Bola voli adalah olahraga permainan yang dimainkan oleh dua grup berlawanan. Masingmasing grup memiliki enam orang pemain. Terdapat pula variasi permainan bola voli pantai yang masing-masing grup hanya memiliki dua orang pemain.

C. Aturan permainan dari bola voli

1. Jika pihak musuh bisa memasukkan bola ke dalam daerah kita maka kita kehilangan bola dan musuh mendapatkan senilai

2. Serve yang kita lakukan harus bisa melewati net dan masuk ke daerah musuh. Jika tidak, maka musuh pun akan mendapat nilai

a) Service

Servis pada jaman sekarang bukan lagi sebagai awal dari suatu permainan atau sekedar menyajikan bola, tetapi sebagai suatu serangan pertama bagi regu yang melakukan servis. Servis terdiri dari servis tangan bawah dan servis tangan atas.Servis tangan atas dibedakan lagi atas tennis servis,floating dan cekis.

1) servis tangan bawah

- Mula-mula pemain berdiri dipetak servis dengan kaki kiri lebih kedepan dari kaki kanan.

- Bola dipegang dengan tangan kiri

- Bola dilambungkan tidak terlalu tinggi,tangan kanan ditarik ke bawah belakang

- Setelah bola kira-kira setinggi pinggang,lengan kanan diayunkan lurus kedepan untuk memukul bola

- Telapak tangan menghadap bola dan tangan ditegangkan untuk mendapat pantulan yang sempurna,tangan dapat pula menggenggam.

2) Tennis servis

- Sikap persiapan dimulai dengan mengambil posisi kaki kiri lebih kedepan, kedua lutut agak rendah

- tangan kiri dan kanan bersama-sama memegang bola,tangan kirimenyangga bola,tangan kanan diatas bola.

- bola dilambungkan dengan tangan kiri kira-kira 1/2 meter diatas kepala 
- tangan kanan ditarik kebelakang atas kepala,menghadap depan

- lakukan gerakan seperti mensmesh bola,perhatian terpusat pada bola

- lecutan tangan diperlukan pada saat p[erkenaan bola.

3) floating servis

- Posisi kaki sama seperti tennis servis

- Tangan kiri memegang bola dan tangan kanan disamping setinggi pelipis

- Dengan tangan kiri bola dilambungkan ssedikit kesamping kanan tidak terlalu tinggi

- Setelah bola melambung keatas setinggi kepala, tangan kanan dipukulkan pada bagian tengah bola.

- Pukulan float dapat dilakukan dengan beberapa cara:

$\checkmark$ Dengan tumit tangan

$\checkmark$ Dengan tangan, dimana ibu jari dilipat kedalam dan menempel pada telapak tangan

$\checkmark$ Memukul dengan tangan tergenggam.

4) Cekis

- Sikap permulaan dengan mengambil sikap berdiri menyamping dengan tubuh bagian kiri lebih dekat kejaring.

- Bola dipegang tangan kiri dan kanan.

- Saat bola dilambungkan, badan diliukkan sedikit kebelakang dan lutut ditekuk

- Kkedua tangan dijulurkan kearah samping bawah kanan dalam keadaan memegang bola.

- Bola dilambung keatas kepala dengan kedua belah tangan.

- Setelah bola lepas, tangan kanan ditarik kesamping kanan bawah, liukkan badan kekanan.

- Berat badan ada dikaki kanan,telapak tangan menghadap keatas

- Setelah bola ada pada jangkauan tangan,secepatnya bersama sama lengan,liukkan badan kesamping kiri

- Perkenaan bola bagian bawah belakang bola,pukulan bola dibantu liukkan badan dan lecutan tangan. 
Service ada beberapa macam:

1) Service atas adalah service dengan awalan melemparkan bola ke atas seperlunya. Kemudian Server melompat untuk memukul bola dengan ayunan tangan dari atas.

2) Service bawah adalah service dengan awalan bola berada di tangan yang tidak memukul bola. Tangan yang memukul bola bersiap dari belakang badan untuk memukul bola dengan ayunan tangan dari bawah.

3) Service mengapung adalah service atas dengan awalan dan cara memukul yang hampir sama. Awalan service mengapung adalah melemparkan bola ke atas namun tidak terlalu tinggi (tidak terlalu tinggi dari kepala). Tangan yang akan memukul bola bersiap di dekat bola dengan ayunan yang sangat pendek.

Yang perlu diperhatikan dalam service

1) Sikap badan.

2) Lambung keatas harus sesuai dengan kebutuhan.

3) Saat kapan harus memukul Bola.

b) Passing

Passing Bawah ( Pukulan/penganmbilan tangan kebawah ) Sikap badan jongkok, lutut agak ditekuk. Tangan dirapatkan, satu dengan yang lain dirapatkan.

Gerakan tangan disesuaikan dengan keras/lemahnya kecepatan bola.

Passing Keatas ( Pukulan/penganmbilan tangan keatas ) Sikap badan jongkok, lutut agak ditekuk.

Badan sedikit condong kemuka, siku ditekuk jari-jari terbuka membentuk lengkungan setengah bola. Ibu jari dan jari saling berdekatan membentuk segitiga.

Penyentuhan pada semua jari2 dan gerakannya meluruskan kedua tangan

c) Smash (spike)

Dengan membentuk serangan pukulan yang keras waktu bola berada diatas jaring, untuk dimasukkan ke daerah lawan. Untuk melakukan dengan baik perlu memperhatikan faktor-faktor berikut: awalan, tolakan, pukulan, dan pendaratan. 
d) Membendung (Bloking)

Dengan daya upaya di dekat jaring untuk mencoba menahan/menghalangi bola yang datang dari daerah lawan.

e) Kedudukan Pemain (Posisi Pemain)

Pada waktu service kedua regu harus berada dalam lapangan / didaerahnya masing2 dalam 2 deret kesamping. Tiga deret ada di depan dan tiga deret ada di belakang

D. Teknik Dasar Permainan Bola Voli

a) Service

Service merupakan teknik dasar bola voli yang harus di pelajari oleh setiap pemain pemula. Teknik service dilakukan dengan cara pemain berdiri pada garis belakang lapangan dengan melemparkan bola ke udara kemudian bola dipukul melewati net ke arah lapangan area permainan lawan. Tujuan melakukan service yaitu memukul bola melewati net dengan memilih area yang kosong atau mengarah ke pemain yang terlihat lemah agar tidak bisa diterima oleh pemain lawan supaya tim mendapatkan poin.

b) Passing

Passing juga dapat dikenal dengan sebutan reception adalah sebuah usaha yang dilakukan oleh pemain dalam sebuah tim untuk menerima, mengendalikan dan menahan servis yang dilakukan oleh pemain lawan dalam bentuk penyerangan. Teknik passing terbagi menjadi 2 macam yaitu passing bawah dan passing atas.

c) Smash atau Spike

Smash atau spike adalah teknik dasar bola voli yang dilakukan memukul bola menggunakan kekuatan penuh dengan melompat, kemudian bola diarahkan ke area permainan lawan yang kosong. Teknik ini dalam permainan bola voli merupakan pukulan ketiga.

Urutan dalam menerima bola adalah bola pertama biasa dilakukan dengan menggunakan passing bawah, kemudian bola kedua dengan passing atas dan yang ketiga dengan melakukan teknik smash. seorang pemain spiker atau penyerang dalam tim idealnya memiliki postur badan 
dan lompatan yang tinggi. Hal ini karena saat melakukan teknik smash pemain harus melakukan lompatan dan memukul bola ketika berada di puncak ketinggian.

d) Block

Teknik Block digunakan untuk menahan atau mencegah serangan yang dilakukan oleh tim lawan. Pertahanan dapat dilakukan dengan cara menggunakan kedua tangan dan dibarengi dengan lompatan yang tinggi, kemudian menahan bola agar tidak masuk ke dalam area permaian sendiri.

Dalam bermain bola voli teknik ini sangat diperlukan oleh tim, oleh karena itu setiap pemain wajib menguasai teknik block dengan baik. Langkah yang harus dilakuakan untuk melakukan teknik blok adalah berdiri dengan posisi kaki yang sejajar, disaat yang bersamaan kedua tangan berada di depan dada dengan posisi tangan menghadap ke arah net, kemudian melakukan lompatan dan mengikuti arah bola yang akan di pukul oleh pemain lawan

\section{E. Posisi Pemain Bola Voli}

Dalam permaian bola voli pelatih harus menyusun strategi dengan pintar supaya penguasaan pertandingan bisa dikendalikan. Termasuk pengaturan posisi antara pemain yang satu dengan pemain lainya. Berikut ini posisi pemain yang berperan penting dalam setiap pertandingan bola voli.

\section{a) Posisi Pemain Bola Voli Tosser (setter)}

Tosser adalah pemain yang memiliki tugas untuk mengoper bola kepada teman satu timnya dan mengatur ritme jalanya permainan.

b) Posisi Pemain Bola Voli Spikker (smash)

Spikker adalah pemain yang memiliki tugas untuk memukul bola agar jatuh di area pertahanan permainan lawan

c) Posisi Pemain Bola Voli Libero

Libero adalah pemain yang memiliki tugas bertahan dengan cara menahan bola dari pukulan lawan. Pemain ini bisa bebas dalam keluar masuk pertandingan, namun tidak boleh melakukan 
teknik smash. Pemain libero hanya boleh menggunakan passing bawah atau passing atas jika bola ingin melewati net.

d) Posisi Pemain Bola Voli Defender (pemain bertahan)

Defender adalah pemain yang memiliki tugas bertahan untuk menerima serangan dari tim lawan.

F. Perasarana Permainan Bola Voli

1. Ukuran Lapangan Permainan Bola Voli

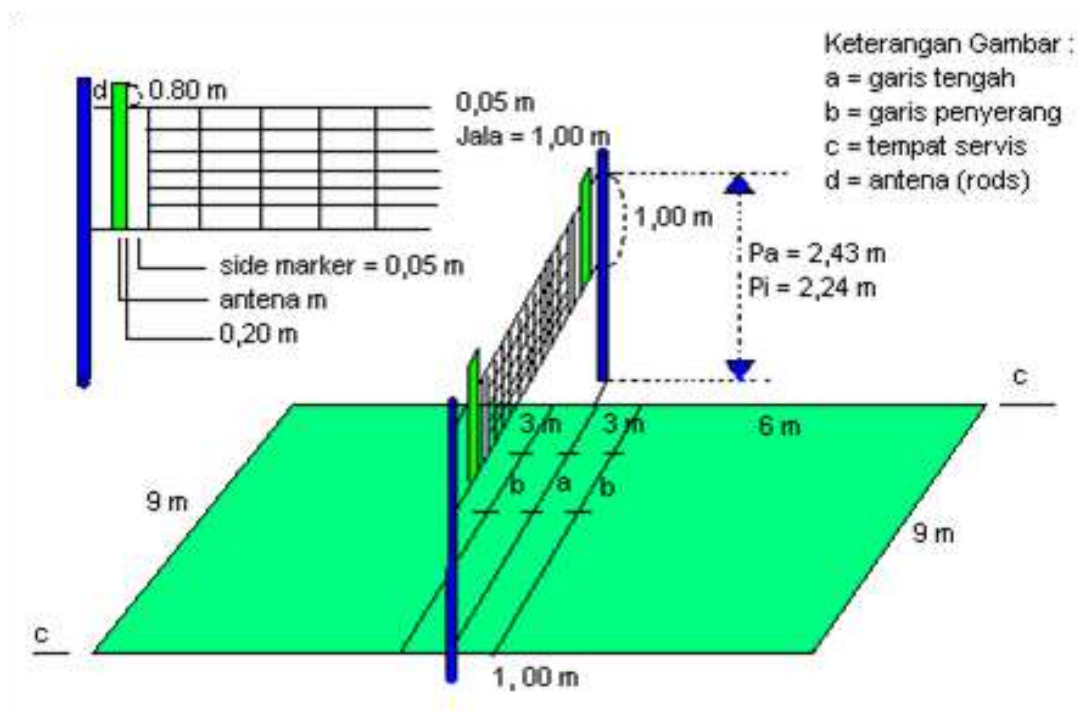

Lapangan permainan bola voli berbentuk persegi panjang dengan ukuran panjang $18 \mathrm{~m}$ dan lebar $9 \mathrm{~m}$, semua garis batas lapangan, garis tengah, garis daerah serang adalah $3 \mathrm{~m}$ (daerah depan). Garis batas itu diberi tanda batas dengan menggunakan tali, kayu, cat/kapur, kertas yang lebarn ya tidak lebih dari $5 \mathrm{~cm}$. lapangan permainan bola voli terbagi menjadi dua bagian sama besar yang masing-masing luasnya 9 x 9 meter. Di tengah lapangan dibatasi garis tengah yang membagi lapangan menjadi dua bagian sama besar. Masing-masing lapangan terdiri dari atas daerah serang dan daerah pertahanan.

Daerah serang yaitu daerah yang dibatasi oleh garis tengah lapangan dengan garis serang yang luasnya 9 × 3 meter. 


\section{Daerah Servise}

Daerah service adalah daerah selebar 9 meter di belakang setiap garis akhir. Daerah ini dibatasi oleh dua garis pendek sepanjang $15 \mathrm{~cm}$ yang dibuat $20 \mathrm{~cm}$ di belakang garis akhir, sebagai kepanjangan dari garis samping. Kedua garis pendek tersebut sudah termasuk di dalam batas daerah service, perpanjangan daerah service adalah kebelakang sampai batas akhir daerah bebas.

3. Jaring (Net)

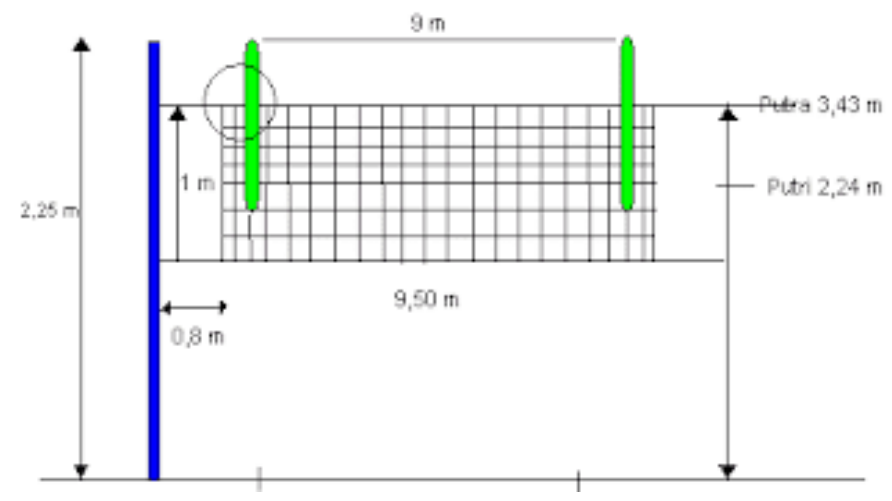

Jaring untuk permainan bola voli berukuran tidak lebih dari 9,50 meter dan lebar tidak lebih dari 1,00 meter dengan petak-petak atau mata jaring berukuran 10 x $10 \mathrm{~cm}$, tinggi net untuk putra 2,43 meter dan untuk putri 2,24 meter, tepian atas terdapat pita putih selebar $5 \mathrm{~cm}$.

\section{Antene Rod}

Di dalam pertandingan permainan bola voli yang sifatnya nasional maupun internasional, di atas batas samping jaring dipasang tongkat atau rod yang menonjol ke atas setinggi $80 \mathrm{~cm}$ dari tepi jaring atau bibir net. Tongkat itu terbuat dari bahan fibergelas dengan ukuran panjang $180 \mathrm{~cm}$ dengan diberi warna kontras. 


\section{Bola}

Bola harus bulat terbuat dari kulit yang lentur atau terbuat dari kulit sintetis yang bagian dalamnya dari karet atau bahan yang sejenis. Warna bola harus satu warna atau kombinasi dari beberapa warna. Bahan kulit sintetis dan kombinasi warna pada bola dipergunakan pada pertandingan resmi internasional harus sesuai dengan standar FIVB.

Keliling bola 64 - $67 \mathrm{~cm}$ dan beratnya 260 - 280 grm, tekanan didalam bola harus 0, 39 - 0, 325 kg/cm2 (4,26 - 4,61 Psi) (294,3 - 318,82 mbar/hpa).

6. Pemain

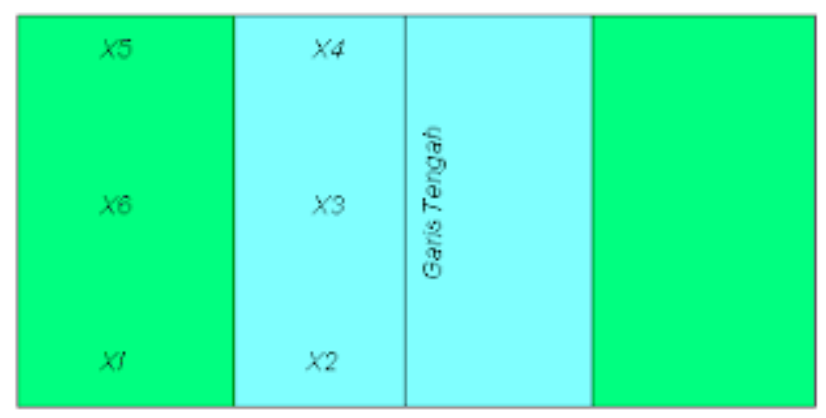

Jumlah pemain dalam lapangan permainan sebanyak 6 orang setiap regu dan ditambah 5 orang sebagai pemain cadangan dan satu orang pemain libero. Satu tim maksimal terdiri dari 12 pemain, saru coach, satu sistem coach, satu trainer, dan satu dokter medis, kecuali libero, satu dari para pemain adalah kapten tim, dia harus diberi tanda dalam score sheet.

Hanya pemain terdaftar dalam score sheet dapat memasuki lapangan dan bermain dalam pertandingan. Pada saat coach dan kapten tim menandatangani scoresheet pemain yang terdaftar tidak dapat diganti.

\section{G. Cara Permainan}

Permainan ini dimainkan oleh 2 tim yang masing-masing terdiri dari 6 orang pemain dan berlomba-lomba mencapai angka 25 terlebih dahulu.

Dalam sebuah tim, terdapat 4 peran penting, yaitu tosser (atau setter), spiker (smash), libero, dan defender (pemain bertahan). Tosser atau pengumpan adalah orang yang bertugas untuk mengumpankan bola kepada rekan-rekannya dan mengatur jalannya permainan. Spiker bertugas 
untuk memukul bola agar jatuh di daerah pertahanan lawan. Libero adalah pemain bertahan yang bisa bebas keluar dan masuk tetapi tidak boleh men-smash bola ke seberang net. Defender adalah pemain yang bertahan untuk menerima serangan dari lawan.

Permainan voli menuntut kemampuan otak yang prima, terutama tosser. Tosser harus dapat mengatur jalannya permainan. Tosser harus memutuskan apa yang harus dia perbuat dengan bola yang dia dapat, dan semuanya itu dilakukan dalam sepersekian detik sebelum bola jatuh ke lapangan sepanjang permainan. Permainan ini dimainkan oleh 2 tim yang masing-masing terdiri dari 6 orang pemain dan mengusahakan untuk mencapai angka 25 terlebih dahulu untuk memenangkan suatu babak.

a) Urutan Serve

1) Penghitungan angka

Aturan permainan dari bola voli adalah:

- Jika pihak musuh bisa memasukkan bola ke dalam daerah kita maka kita kehilangan bola dan musuh mendapatkan nilai

- Serve yang kita lakukan harus bisa melewati net dan masuk ke daerah musuh. Jika tidak, maka musuh pun akan mendapat nilai

2) Sistem Pertandingan

a) Sistem pertandingan menggunakan sistem setengah kompetisi yang terdiri dari 8 tim dan akan disitribusikan ke dalam 2 (dua) group, masing-masing group terdiri dari 4 (empat) tim.

b) Setiap tim terdiri dari 10 pemain meliputi 6 pemain inti yang bermain di lapangan dan 4 pemain cadangan.

c) Pergantian pemain inti dan cadangan pada saat pertandingan berlangsung tidak dibatasi.

d) Pertandingan tidak akan ditunda apabila salah satu atau lebih dari satu anggota tim sedang bermain untuk cabang olahraga yang lain.

e) Jumlah pemain minimum yang boleh bermain di lapangan adalah 4 orang.

f) Apabila di lapangan terdapat kurang dari 4 orang, maka tim yang bersangkutan akan dianggap kalah.

g) Setiap pertandingan berlangsung 3 babak (best of three), kecuali pada 2 babak sudah di pastikan pemenangnya maka babak ke tiga tidak perlu dilaksanakan. 
h) Sistem hitungan yang digunakan adalah 25 rally point. Bila poin peserta seri (24-24) maka pertandingan akan ditambah 2 poin. Peserta yg pertama kali unggul dengan selisih 2 poin akan memenangi pertandingan.

i) Kemenangan dalam pertandingan penyisihan mendapat nilai 1 . Apabila ada dua tim atau lebih mendapat nilai sama, maka penentuan juara group dan runner-up akan dilihat dari kualitas angka pada tiap-tiap set yang dimainkan.

j) Kesalahan meliputi:

- Pemain menyentuh net atau melewati garis batas tengah lapangan lawan.

- Tidak boleh melempar ataupun menangkap bola.

- Bola voli harus di pantulkan tanpa mengenai dasar lapangan.

- Bola yang dipantulkan keluar dari lapangan belum dihitung sebagai out sebelum menyentuh permukaan lapangan.

- Pada saat servis bola yang melewati lapangan dihitung sebagai poin bagi lawan, begitu juga sebaliknya penerima servis lawan yang membuat bola keluar dihitung sebagai poin bagi lawan.

- Seluruh pemain harus berada di dalam lapangan pada saat serve dilakukan.

- Pemain melakukan spike di atas lapangan lawan.

- Seluruh bagian tubuh legal untuk memantulkan bola kecuali dengan cara menendang.

- Para pemain dan lawan mengenai net 2 kali pada saat memainkan bola dihitung sebagai double faults.

- Setiap team diwajibkan bertukar sisi lapangan pada saat setiap babak berakhir. Dan apabila dilakukan babak penetuan (set ke 3) maka tim yang memiliki nilai terendah boleh meminta bertukar lapangan sesaat setelah tim lawan mencapai angka 13.

- Time out dilakukan hanya 1 kali dalam setiap babak dan berlangsung hanya 1 menit.

- Diluar dari aturan yang tertera disini, peraturan permainan mengikuti peraturan internasional. 


\section{BAB III}

\section{PENUTUP}

\section{A. Kesimpulan}

Untuk bermain bola voli tidak menuntut kemampuan fisik yang tinggi, yang diperlukan hanyalah semangat untuk mau mengejar bola kemanapun jatuhnya. Berlahan-lahan teknik yang diperlukan untuk bermain voli itu akan tumbuh dengan sendirinya.

\section{B. Saran}

Bermain voli juga menuntut kemampuan otak yang prima, terutama tosser. Tosser harus dapat mengatur jalannya permainan. Tosser harus memutuskan apa yang harus dia perbuat dengan bola yang dia dapat, dan semuanya itu dilakukan dalam sepersekian detik sebelum bola jatuh ke lapangan sepanjang permainan. Jadi hanya orang bodoh yang mengatakan bahwa yang penting dalam bermain voli adalah lompatan yang tinggi, passing yang bagus, dan pukulan yang keras. Tanpa otak maupun kemauan yang cukup mustahil semua itu bisa tercapai 


\section{DAFTAR PUSTAKA}

Irwansyah.2004.Sehat dan Tangkas berolahraga pendidikkan jasmani.Bandung: Grafindo Media Pratama

Husni, Agusta.tt. Buku Pintar Olaharaga. Jakarta: Mawar Gempita

Kantor Menteri Negara Pemuda Olahraga. 1999. Petunjuk Pelaksanaan Senam Kesegaran

Jasmani 2000.

Brown, Richard L. dan Joe Henderson.2001.Bugar dengan Lari. Jakarta : Rajagrafindo Persada.

Direktorat Pendidikan Dasar.1996. Metode Pengajaran Pendidikan Jasmani dan Kesehatan di Sekolah dasar. Jakarta : Mawar Gempita.

Kokasih, Engkos. 1985. Olahraga; Teknik dan Program Latihan. Jakarta: Akademi Pressindo 